\title{
Effect of dental caries and the consequential variation in blood parameters on the anaerobic performance of rowing athletes
}

\author{
Osman HAMAMCILAR', Tuğba KOCAHAN'', Bihter AKINOĞLU², Adnan HASANOĞLU' \\ ${ }^{1}$ Department of Health Services, Center of Athlete Training and Health Research, Sports General Directorship, The Ministry of Youth and Sports, \\ Ankara, Turkey \\ ${ }^{2}$ Department of Physiotherapy and Rehabilitation, Faculty of Health Sciences, Ankara Yıldırım Beyazıt University, Ankara, Turkey \\ Correspondence \\ Bihter AKINOĞLU \\ Ankara Yıldırım Beyazıt Üniversitesi, Sağlık Bilimleri Fakültesi, Fizyoterapi ve Rehabilitasyon Bölümü 0600 Ankara, Türkiye \\ e-mail:rgkardelen@yahoo.com
}

\begin{abstract}
This study aimed to investigate the effect of dental caries and the subsequent poor oral health on the blood parameters and anaerobic performance of athletes. The study was conducted on 30 elite rowing athletes (18 male and 12 female) who had a DMF-T index value of 3.9 after an oral check-up. The athletes were split into two groups: the study group, which consisted of athletes having four or more infected tooth; and the control group with athletes having one or no infected tooth. The study group consisted of 15 athletes ( 9 male and 6 female) with infected tooth number $\geq 4$, DMF-T value of 7 , and a mean age of $18.73 \pm 1.05$ years, whereas the control group consisted of also 15 athletes ( 9 male and 6 female) with DMF-T value of 0.9 and a mean age of $18.26 \pm 2.01$ years. The anaerobic capacity of athletes was measured using the Wingate test (WanT). The two demographically similar groups had no difference in their blood parameters and urine density values $(P>0.05)$. Also, no statistically significant difference in the WanT results was observed between the two groups, and WanT performances were similar in both groups $(P>0.05)$. Further, the superficial decay at the enamel and dentine levels did not negatively impact the anaerobic performance of athletes. On the contrary, it was suggested that studies should be conducted on the effect of severe dental caries at the pulpal level on athletic performance, which may also cause chronic inflammation.
\end{abstract}

Key words: Athlete, Dental caries, DMF-T, performance, sport, Wingate test

\section{INTRODUCTION}

It is important for an athlete to maintain good general health so as to maximize athletic performance. Oral health is a vital part of systemic health and quality of life $(1,2)$. Studies suggested that athletes having poor oral health also might have low athletic performance $(3,4)$.

Dental caries is linked to several factors, including dental plaques in the mouth, nutritional habits, fluoride content, $\mathrm{pH}$, enamel structure, and dominance of Streptococcus mutans. The risk factors causing dental caries are low oral hygiene levels and other factors that negatively affect dental health, such as low socioeconomic status, age (kids, young adults, and elderly people having higher risks), dry mouth (reduced saliva), erosion of dental fillings, eating disorders, acid reflux, malnutrition, and genetic factors. The factors that reduce the risk are brushing teeth properly, using fluoride toothpaste, using antibacterial medicine, reducing the frequency and quantity of carbohydrate consumption, and increasing saliva flow (5).
Oral health is a part of general health and plays an important role in maintaining life functions and quality of life (6). Dental caries and oral diseases occur as a result of a complicated relationship between the pathogenic microorganisms and the host. They are contagious diseases with the most common multifactorial etiology based on the World Health Organization's (WHO) database (7). The initial immune response to the deterioration of oral health as a result of dental caries is the increase in the levels of pro-inflammatory cytokines, including interleukin (IL)-6, IL-4, IL-1- $\beta$, IL$1-a$, lymphotoxin- $a$, and TNF- $a$. This increase in cytokine levels is a risk factor for systemic diseases (8).

Maximum voluntary muscle flexing, strength, force development speed, and dynamic force are used as an index for the muscle strength development capacity (9). This index also provides enough information on muscle strength and performance in general terms. Muscle strength is a good indication of muscle performance and functional capacity (10). The factors 
affecting muscle performance include energy formation (aerobic-anaerobic), neuromuscular transmission, muscle health, and nutritional and psychological factors. The present study on exercise physiology suggested many bioindicators that affected athletic performance and might negatively impact athletes' health. High levels of cytokines in plasma, as one of these bioindicators, occur simultaneously with dental caries and play an important role in muscle fatigue during exercise and oxidative stress development after exercise (11). High levels of cytokines in plasma are related to low muscle strength (12). One of the studies suggested that the pathogens that caused dental caries not only caused other diseases by traveling through the circulatory system but also caused sports injuries.

In addition to the local changes associated with dental caries, an increase in C-reactive protein, which is an acute-phase protein, and cytokine levels also occurs. This may lead to the loss of strength in skeletal muscles and a reduction in aerobic performance (13). Moreover, athletic and exercise performance is also negatively affected (14). Nevertheless, high scores of dental caries, DMF-T index values, and periodontal diseases are associated with lower FEV1/FVC\% values, lower athletic performance, and muscle, tendon, and bone injuries in athletes (15).

Anaerobic capacity is defined as the work capacity that skeletal muscles develop using energy transfer systems during maximal and supramaximal exercises. This effort per unit time is called anaerobic power ( $\mathrm{kg} / \mathrm{s}, \mathrm{kg} / \mathrm{min}$, watt). It is not possible to directly measure anaerobic power and anaerobic capacity. The Wingate anaerobic test (WanT) is the most commonly used laboratory method for measuring anaerobic power because it includes larger muscle groups and can measure higher values $(16,17)$.

Available studies $(8,11,13-15)$ hypothesized that a link existed between dental caries and anaerobic performance. The purpose of this study was to investigate the effect of dental caries and the subsequent poor oral health on the blood parameters and anaerobic performance of athletes.

\section{MATERIALS AND METHODS}

This study was conducted in the Ministry of Youth and Sports (GSB), General Directorate of Sports (SGM), Department of Health Affairs and Athlete Education, Health and Research Center with the formal approval of GSB, SGM Department of Health Affairs' decree of 39746592-100[020]-E.51401 dated January 22, 2019. All participating athletes were informed about the research and testing and were asked to read and sign the "Informed Consent" and "General Consent" forms, which were drafted in line with the Helsinki Declaration Principles. The selection criteria for the participating athletes included the following: not having any acute or chronic diseases, not having any systemic diseases, not having any hemoglobinopathy, not undergoing any medical procedure within the preceding year, not having received blood transfusion in the last 6 months, not sustaining any injuries on the lower extremities, agreeing to follow the parameters to be implemented during the studies, and volunteering to participate in the studies. Athletes not meeting any of the aforementioned criteria were excluded from the study. The demographic data of the athletes, who accepted to participate in the study, were initially recorded. The participants had similar sociocultural characteristics, attended the same schools, and performed the same practices. Also, they had similar nutritional habits and consumed similar types of food. They did not have any known medical conditions. The athletes underwent a dental examination by a dentist after blood and urine tests in the morning before breakfast. The anaerobic strength test was also conducted on the same day. The demographic data of athletes, who participated in the study, are provided in Table 1.

\section{Dental examination}

The evaluation of the dental health was performed based on the WHO criteria related to decay (D), loss $(\mathrm{M})$, restoration $(\mathrm{F})$, and "DMF-T index," which corresponded to the number of infected teeth per person in the population groups. The dental examination was performed by the same dentist in a dental clinic using a sterile dental mirror.

The 30 athletes ( 18 male and 12 female) with 3.9 DMF-T index values were split into 2 groups: the study group (number of cavities $\geq 4$ ) and the control group (number of cavities $<1$ ). During the dental examination, all athletes were found to have cavities at the enamel and dentine levels. The study group comprised 15 athletes (9 male and 6 female) who had a DMF-T index value of 7 , average age $18.73 \pm 1.05$ years, and $\geq 4$ cavities. However, the control group comprised 15 athletes ( 9 male and 6 female) who had a DMF-T index value of 0.9 and the average age of $18.26 \pm 2.01$ years. The control group had the target DMF-T index value 
Table 1: Characteristics of athletes and oral data.

\begin{tabular}{llll}
\hline & $\begin{array}{l}\text { Study group } \\
(\mathrm{n}=15)\end{array}$ & $\begin{array}{l}\text { Control group } \\
(\mathrm{n}=15)\end{array}$ & $\mathrm{P}^{*}$ \\
\hline Age (year) & $18.73 \pm 1.05$ & $18.26 \pm 2.01$ & 0.111 \\
Height $(\mathrm{cm})$ & $180.60 \pm 8.84$ & $180.13 \pm 7.35$ & 0.876 \\
Body weight $(\mathrm{kg})$ & $76.53 \pm 10.05$ & $73.93 \pm 10.22$ & 0.488 \\
BMl $\left(\mathrm{kg} / \mathrm{m}^{2}\right)$ & $26.95 \pm 4.68$ & $27.42 \pm 3.84$ & 0.765 \\
Infected tooth number & $6.93 \pm 2.63$ & $0.86 \pm 1.12$ & $0.000^{* *}$ \\
\hline
\end{tabular}

*Independent-samples t test, " $\mathrm{P}<0.05$. BMI, Body mass index.

that corresponded to $<1$ number of cavities based on the DSO 2020 data.

\section{Blood analyses}

Two tubes [one with EDTA and the other with a clot activator (SST II Advance)] of blood were drawn from the antecubital vein for checking the complete blood count and iron and ferritin levels. The blood analyses were conducted using the automatic blood count machine (Sysmex Corp. XN-1000 SA-0 Kobe, Japan) and the biochemical autoanalyzer (Randox RX Imola, Japan).

Evaluation of anaerobic capacity: The anaerobic capacity of the athletes was assessed using the anaerobic strength test called WanT.

The WanT test was performed to measure explosive strength, endurance, and muscular fatigue; to collect information on the muscular metabolism during short and high-intensity exercises; and to evaluate athletic performance. For the WanT test, a Monark $891 \mathrm{E}$ model leg bicycle ergometer with a basket, which was attached to a computer running a customized software, was used. Prior to testing, the seat and pedal length was adjusted for each athlete. The load corresponding to $7.5 \%$ of lower-extremity Wants body weight was automatically calculated by the computer and inserted into the bicycle's basket. A warm-up protocol involving 3-min continuous cycling with a speed of $60-80 \mathrm{rpm}$ was followed prior to testing. During the last $5 \mathrm{~s}$ of each minute during the $3-\mathrm{min}$ warm-up, the cycling speed was increased to $120-160$ rpm. Following the warm-up, the athletes were asked to do stretching for $2 \mathrm{~min}$ so as to recover. When the athlete was ready for testing, he was asked to pedal for $30 \mathrm{~s}$ against the basket weight. At the end of the 30-s period, the number of cycles and the loading data were used to calculate work $=$ anaerobic capacity $(\mathrm{J}=$
Joule). Using the mathematical average of total work, average work = anaerobic strength $(\mathrm{W}=$ watt $)$ was calculated. Peak power is the maximum strength value reached during any of the 5-s periods (particularly the first few seconds) of WanT testing. Peak power is an indication of the anaerobic energy capacity. On the contrary, minimum power is the minimum value during any of the 5-s periods (usually the last seconds) lasting $30 \mathrm{~s}$. This test helped calculate the fatigue index (Peak power - Minimum power/Peak power) $\times 100(\%$ Fatigue index). The tests were concluded with a 3-min cooldown by pedaling at a low intensity.

\section{Statistical analysis}

The collected data were analyzed using a statistical software called SPSS for Windows Release 20.0 (Statistical Package for Social Sciences Inc., IL, USA). The deterministic statistics of the variables were calculated, and the average values of the variables were shown as arithmetic mean \pm standard deviation. The two groups were compared using the paired-samples $\mathrm{t}$ test. The $P$ value was taken as $<0.05$ in all statistical analyses.

\section{RESULTS}

The study showed no differences in age, height, body weight, and body mass index (BMI) parameters between the athletes of both groups; all were simi$\operatorname{lar}(P>0.05)$. The number of an infected tooth was higher in the study group than in the control group $(P<0.05)$ (Table 1).

The parameters obtained following the complete blood count and iron and ferritin blood tests were similar in both the groups $(P>0.05)$ (Table 2).

The urine density results obtained following the complete urine tests were similar in both the groups $(P>0.05)$ (Table 3). 
Hamamcılar, Kocahan, Akınoğlu, Hasanoğlu

Table 2: Comparison of complete blood count parameters of athletes.

\begin{tabular}{llll}
\hline & Study group $(\mathrm{n}=15)$ & Control group $(\mathrm{n}=15)$ & $\mathrm{P}^{*}$ \\
\hline RBC $\left(\times 10^{6} / \mathrm{uL}\right)$ & $5.13 \pm 0.54$ & $5.21 \pm 0.61$ & 0.702 \\
Hemoglobin $(\mathrm{g} / \mathrm{dL})$ & $15.19 \pm 1.25$ & $15.29 \pm 1.42$ & 0.840 \\
Hematocrit $(\%)$ & $43.09 \pm 3.38$ & $42.75 \pm 3.83$ & 0.794 \\
MCV $(\mathrm{fL})$ & $84.23 \pm 3.46$ & $82.46 \pm 4.63$ & 0.245 \\
MCH $(\mathrm{pg})$ & $29.69 \pm 1.24$ & $29.58 \pm 1.74$ & 0.848 \\
RDW $(\%)$ & $12.76 \pm 0.83$ & $12.61 \pm 0.90$ & 0.647 \\
Iron $(\mu \mathrm{g} / \mathrm{dL})$ & $114.22 \pm 46.08$ & $117.02 \pm 54.31$ & 0.880 \\
Ferritin $(\mathrm{ng} / \mathrm{mL})$ & $52.23 \pm 32.88$ & $48.50 \pm 30.19$ & 0.749 \\
\hline
\end{tabular}

"Independent-samples t test. MCH: Mean corpuscular hemoglobin MCV: Mean corpuscular volume RBC: Red blood cell RDW: Red cell distribution widths; $\mathrm{X} \pm \mathrm{SD}$, average \pm standard deviation.

Table 3: Comparison of urine density results of athletes

\begin{tabular}{llll}
\hline & Study group $(n=15)$ & Control group $(n=15)$ & $P^{*}$ \\
\hline Urine density & $1015.30 \pm 5.16$ & $1015.01 \pm 5.61$ & 0.404 \\
\hline
\end{tabular}

When the groups were compared in terms of lower-extremity WanT parameters, the parameters did not show any statistically significant difference $(P$ $>0.05$ ) (Table 4).

\section{DISCUSSION}

The study showed that the superficial dental caries at the enamel and dentine levels did not negatively impact the anaerobic performance and blood parameters of athletes.

Oral health is an important part of general health, and the oral cavity is the window to the general health. Systemic and oral diseases are all related. It has been scientifically proven that any inflammatory oral disease may also affect other parts of the body $(1,2)$. Oral diseases have a negative effect on the skeletal, cardiovascular, respiratory, and digestive systems $(1,2)$.

The factors contributing to the poor oral health of the athletes include nutritional habits, consumption of sports drinks, and reduced saliva during exercise (dehydration due to rapid breathing and perspiration) (18-21). Some other factors causing poor oral health include, but are not limited to, nutritional habits during exercise periods, frequency of food consumption, consumption of drinks having high sugar and acid contents, individual saliva production and blocking capacities, frequency of brushing teeth, and so forth. One of the studies demonstrated that soccer players had an average DMF-T index value of $8.2 \pm 5.0$ despite

Table 4: Comparison of complete blood count parameters of athletes.

\begin{tabular}{llll}
\hline & $\begin{array}{l}\text { Study group } \\
(n=15)\end{array}$ & $\begin{array}{l}\text { Control group } \\
(n=15)\end{array}$ & $P^{*}$ \\
\hline Peak power (watt) & $924.91 \pm 229.86$ & $940.65 \pm 240.82$ & 0.856 \\
Peak power (watt/kg) & $12.03 \pm 2.41$ & $12.62 \pm 2.06$ & 0.475 \\
Avarage power (watt) & $656.61 \pm 143.30$ & $643.60 \pm 163.57$ & 0.818 \\
Avarage power (watt/kg) & $8.53 \pm 1.19$ & $8.60 \pm 1.27$ & 0.872 \\
Mean power (watt) & $417.02 \pm 141.01$ & $395.84 \pm 106.77$ & 0.646 \\
Mean power (watt/kg) & $5.32 \pm 1.43$ & $5.31 \pm 1.10$ & 0.977 \\
\hline
\end{tabular}

*Independent-samples $\mathrm{t}$ test. 
undergoing periodic dental examination and followup (22). During the 2012 London Summer Olympics, a study was conducted on the elite athletes using a clinical dental examination and a short survey at the Dental Clinic in the Olympic Village. Among the 302 athletes included in the study, $55 \%$ had dental caries and $41 \%$ had permanent and unrestorable dental erosion and periodontal infections (76\% gingivitis and $15 \%$ periodontitis). More than $40 \%$ of the athletes reported some form of oral health complaints, $28 \%$ had complaints about their quality of life, and $18 \%$ stated that their exercise and athletic performance was negatively affected due to poor oral health (3).

Dental caries may cause chronic anemia. Dental caries in the oral cavity may cause anemia due to insufficient iron intake as a result of poor nutrition and variation in eating habits. A hypothesis suggests that chronic inflammation, particularly due to pulpitis and dental abscess, may lead to an increase in the production of cytokines. Cytokines such as IL-1 may cause chronic anemia by inhibiting the epitopes in the bone marrow $(7,23)$. Anemia is explained as a hypoproliferative disease due to the reduced plasma iron concentration despite the storage of adequate levels of reticuloendothelial iron. This anemia is a result of cytokine effects, contributing to the response to inflammation (24). Studies showed that dental caries increased cytokine levels in the saliva and the restoration of the tooth reversed it $(8,25,26)$. Different studies further showed that hemoglobin, iron, and ferritin levels were lower in patients with dental caries than in the ones without (27-29). Childhood caries affected nutrition, and children with dental caries had twice as much ferritin deficiency and six times as much hemoglobin deficiency compared with the peers without any decay. Studies showed that the prevalence of iron deficiency anemia was much higher in children with dental caries $(27,30)$. A dental caries is a chronic bacterial infection; studies showed that hemoglobin, iron, and ferritin levels increased when dental caries was cured (27). Another study suggested that erythrocyte levels were not affected by poor oral health (31). The present study suggested that the erythrocyte, hemoglobin, hematocrit, mean corpuscular volume, mean corpuscular hemoglobin, red cell distribution width, and iron and ferritin levels were similar in both the groups. The decays identified in this study were superficial decays at the enamel-dentine level and did not reach pulpal levels. This was the reason why the blood parameters did not show any differences in both the groups. The athletes in both groups had similar nutritional habits and socioeconomic backgrounds. Therefore, insufficient nutrition due to the low socioeconomic status was not an influencing factor. Moreover, the athletes were not required to alter their nutritional habits because the dental caries was not at the pulpal level and involved pain.

In the present study, the dehydration levels of the athletes were evaluated based on the urine density. The urine density in both the groups was similar, and hence no dehydration was detected. The changes in the free plasma volume may also change the hemoglobin concentration. In the event of dehydration, the hemoglobin levels may relatively increase as a result of the decrease in the plasma volume and may mask existing anemia (32). This study concluded that the athletes had no dehydration and the obtained blood parameters reflected the actual values because the urine densities were similar and low in both the groups.

Studies suggested that dental caries and oral infections affected athletic performance negatively and might be associated with sports injuries (muscle, tendon, and bone injuries) (33). The present study attempted to show the relationship between the DMFT index value and the WanT test by evaluating the anaerobic performance of the athletes having high and low DMF-T index values using the WanT test. At the end of the tests, the WanT parameters did not show any difference between the athletes with high and low DMF-T index values. Dental caries in the present study was at enamel-dentine levels and did not include any pulpal-level decays affecting the blood circulation. This study also highlighted the need to investigate the effect of more serious dental caries. Despite other studies stating that dental caries affected the blood parameters (6), no study investigated how the number of teeth with caries affected the blood parameters. Therefore, whether a high number of dental caries affected the blood parameters remained unclear. Despite the fact that the control group in this study had low DMF-T index values, some of the athletes had dental caries. This situation might have affected the results. Therefore, additional studies comparing the performance of athletes with and without dental caries might offer clarifications.

Limitation of the present study: The study showed that the group with high DMF-T index values had no inflammation affecting the anaerobic performance. However, it did not include the analysis of inflammation markers. 
In conclusion, the study showed that having dental caries at the enamel-dentine level and a high DMF-T index value did not significantly affect athletic performance. The blood parameters and WanT performance was similar in the group with DMF-T index values (DMF-T $=7$ ) above the WHO standards and the group with this index value at exactly the WHO standards (DMF-T $=0.9$ ). However, it is believed that any decays at the pulpal level, which is a part of systemic circulation and tooth abscess, should affect athletic performance. More studies on athletes with pulpitis, abscess in the apical region, and periodontal disease should be conducted, including the inflammation markers, muscle strength, and aerobic and anaerobic performance parameters.

\section{REFERENCES}

1. Kane SF. The effects of oral health on systemic health. Gen Dent 2017;65:30-4.

2. Kinane D, Marshall G. Peridonatal manifestations of systemic disease. Australian dental journal 2001;46(1):2-12.

3. Needleman I, Ashley P, Petrie A, Fortune F, Turner W, Jones $J$, et al. Oral health and impact on performance of athletes participating in the London 2012 Olympic Games: a crosssectional study. Br J Sports Med 2013;47(16):1054-8.

4. Ashley P, Di lorio A, Cole E, Tanday A, Needleman I. Oral health of elite athletes and association with performance: a systematic review. Br J Sports Med 2015;49(1):14-9.

5. Yadav K, Prakash S. Dental caries: A microbiological approach. J Clin Infect Dis Pract. 2017;2(1):1-15.

6. Koçanalı B, Ak AT, Çoğulu D. Çocuklarda diş çürüğüne neden olan faktörlerin incelenmesi. Pediatric Research 2014;1(2):76-9.

7. Ebersole JL, Cappelli D. Acute-phase reactants in infections and inflammatory diseases. Periodontology 2000 2000;23(1):19-49.

8. Gornowicz A, Bielawska A, Bielawski K, Grabowska SZ, Wójcicka A, Zalewska $M$, et al. Pro-inflammatory cytokines in saliva of adolescents with dental caries disease. Annals of agricultural and environmental medicine 2012;19(4).

9. Stania M, Król P, Sobota G, Polak A, Bacik B, Juras G. The effect of the training with the different combinations of frequency and peak-to-peak vibration displacement of whole-body vibration on the strength of knee flexors and extensors. Biology of sport 2017;34(2):127.

10. Neil SE, Myring A, Peeters MJ, Pirie I, Jacobs R, Hunt MA, et al. Reliability and validity of the Performance Recorder 1 for measuring isometric knee flexor and extensor strength. Physiotherapy theory and practice 2013;29(8):639-47.

11. Solleveld H, Goedhart A, Bossche LV. Associations between poor oral health and reinjuries in male elite soccer players: a cross-sectional self-report study. BMC Sports Science, Medicine and Rehabilitation 2015;7(1):11.

12. Roubenoff R. Physical activity, inflammation, and muscle loss. Nutrition reviews 2007;65(suppl_3):S208-S12.

13. Calvo AM, Brozoski DT, Giglio FP, Gonçalves PZ, Sant'ana E, Dionísio TJ, et al. Are antibiotics necessary after lower third molar removal? Oral surgery, oral medicine, oral pathology and oral radiology 2012;114(5):S199-S208.

14. Needleman I, Ashley P, Meehan L, Petrie A, Weiler R, McNally $\mathrm{S}$, et al. Poor oral health including active caries in $187 \mathrm{UK}$ professional male football players: clinical dental examination performed by dentists. Br J Sports Med 2016;50(1):41-4.
15. Hamamcilar O, Kocahan T, Akinoğlu B, Hasanoğlu A. Effect of poor oral health on respiratory functions and hence sportive performance. Medical Journal of Islamic World Academy of Sciences 2018;26(3):74-9.

16. McArdlle W, Katch F, Katch V. Essential of exercise physiology. Philadelphia: Lippincott Williams \& Wilkins; 2000.

17. Fox EL, Keteyian SJ, Foss ML. Fox's Physiological Basis for Exercise and Sport:WCB/McGraw-Hill; 1998.

18. Bryant S, McLaughlin K, Morgaine K, Drummond B. Elite athletes and oral health. International journal of sports medicine 2011;32(09):720-4.

19. Coombes JS. Sports drinks and dental. American journal of dentistry 2005;18(2):101-4.

20. Mulic A, Tveit AB, Songe D, Sivertsen $H$, Skaare AB. Denta erosive wear and salivary flow rate in physically active young adults. BMC oral health 2012;12(1):8.

21. Lasisi TJ, Adeniyi AF. Effects of acute exercise on salivary free insulin-like growth factor 1 and interleukin 10 in Sportsmen. African health sciences 2016;16(2):560-6.

22. Suzuki M, Toyoda $H$. Survey of Oral Health Condition in Professional Soccer Players. J Oral Sci Health 2015;2:1-4.

23. Gaur S, Nayak R. Underweight in low socioeconomic status preschool children with severe early childhood caries. Journal of Indian Society of Pedodontics and Preventive Dentistry 2011;29(4):305.

24. Means JR. Recent developments in the anemia of chronic disease. Current hematology reports 2003;2(2):116-21.

25. Menon MM, Balagopal RV, Sajitha K, Parvathy K, Sangeetha GB, Arun $X M$, et al. Evaluation of salivary interleukin- 6 in children with early childhood caries after treatment. Contemporary clinical dentistry 2016;7(2):198.

26. Sharma V, Gupta N, Srivastava N, Rana V, Chandna P, Yadav S, et al. Diagnostic potential of inflammatory biomarkers in early childhood caries-A case control study. Clinica Chimica Acta 2017;471:158-63.

27. Schroth RJ, Levi J, Kliewer E, Friel J, Moffatt ME. Association between iron status, iron deficiency anaemia, and severe early childhood caries: a case-control study. BMC pediatrics 2013;13(1):22.

28. Shaoul R, Gaitini L, Kharouba J, Darawshi G, Maor I, Somri M The association of childhood iron deficiency anaemia with severe dental caries. Acta Paediatrica. 2012;101(2):e76-e9.

29. Clarke M, Locker D, Berall G, Pencharz P, Kenny DJ, Judd P. Malnourishment in a population of young children with severe early childhood caries. Pediatric dentistry 2006;28(3):254-9.

30. Tang R-S, Huang M-C, Huang S-T. Relationship between dental caries status and anemia in children with severe early childhood caries. The Kaohsiung journal of medical sciences 2013;29(6):330-6.

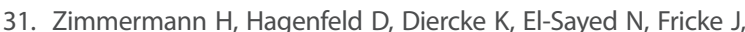
Greiser $\mathrm{KH}$, et al. Pocket depth and bleeding on probing and their associations with dental, lifestyle, socioeconomic and blood variables: a cross-sectional, multicenter feasibility study of the German National Cohort. BMC oral health 2015;15(1):7.

32. Mairbäurl H. Red blood cells in sports: effects of exercise and training on oxygen supply by red blood cells. Frontiers in physiology 2013;4:332.

33. Gay Escoda C, Pereira DMVD, Ardèvol J, Pruna R, Fernandez J, Valmaseda Castellón E. Study of the effect of oral health on physical condition of professional soccer players of the Football Club Barcelona. Medicina Oral, Patología Oraly Cirugia Bucal 2011;16(3):436-439. 